\title{
Corrigenda
}

\section{Modified Girdlestones-Taylor procedure for claw toes in spinal cord injury}

S Ozdolap, KM Mathew, M McClelland and G Ravichandran

Spinal Cord (2006) 44, 813. doi:10.1038/sj.sc.3101966

Correction to: Spinal Cord (2006) 44, 787-790. doi:10.1038/sj.sc.3101924; published online 28 March 2006.

The author name S Ozdolap was published incorrectly in the above article. The correct author list is now shown.

\section{Effects of repeated ejaculations on semen characteristics following spinal cord injury}

R Hamid, P Patki, H Bywater, PJR Shah and MD Craggs

Spinal Cord (2006) 44, 813. doi:10.1038/sj.sc.3102016

Correction to: Spinal Cord (2006) 44, 369-373. doi:10.1038/sj.sc.3101849; published online November $22,2005$.

The authors of the above paper have identified an omission. The paper should have included an Acknowledgements section as is now shown.

\section{Acknowledgements}

This study was kindly part sponsored by ASPIRE. 